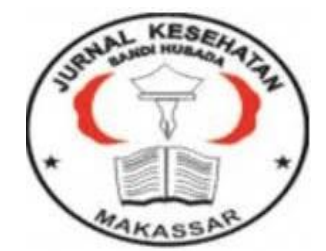

\author{
Jurnal Ilmiah Kesehatan Sandi Husada
}

hhttps://akper-sandikarsa.e-journal.id/JIKSH

Vol 9, No, 1, Juni 2020, pp;116-121

p-ISSN: 2354-6093 dan e-ISSN: 2654-4563

DOI: $10.35816 /$ jiskh.v10i2.232

\title{
Sindrom Premenstruasi terhadap Kinerja Perawat Intensive Care Unit di Rumah Sakit Kota Makassar
}

The Premenstrual Syndrome on the Performance of Nurse Intensive Care Unit in Makassar City Hospital

Ekayanti Hafidah Ahmad

Akademi Keperawatan Makassar

\begin{tabular}{ll}
\hline Artikel Info & \\
\hline Received;16 Maret 2020 & Abstrak \\
Revised:19 Maret 2020 & Tujuan: Studi ini bertujuan untuk mengetahui hubungan sindrom \\
Accepted;20 Maret 2020 & premenstruasi terhadap kinerja perawat icu (intensive care unit) \\
& di rumah sakit makassar. Metode: merupakan penelitian \\
& kuantitatif dengan rancangan cross sectional study. Sampel \\
& sebanyak 36 orang sebagai responden. Pengambilan sampel \\
& dilakukan dengan melalui dua tahap, yakni sampel rumah sakit \\
& dengan purposive sampling. Sampel dihitung berdasarkan rumus \\
& perhitungan besar sampel. Pengambilan data dilakukan dengan \\
& observasional, dokumentasi dengan diary menstruasi dan \\
& wawancara dengan menggunakan kuesioner SPAF (The short \\
& Premenstrual Assesment Form) Hasil: hasil penelitian \\
& menunjukkan bahwa sindrom premenstruasi berhubungan dengan \\
& kinerja perawat p=0,001 (r=0,631) Kesimpulan: studi \\
& menunjukkan ada hubungan antara sindrom premenstruasi \\
& dengan kinerja pada perawat icu (intensive care unit) di rumah \\
& sakit makassar.
\end{tabular}

\begin{abstract}
Aim: This study aims to determine between the relationship of premenstrual syndrome to the performance icu (intensive care unit) nurses in Makassar hospitals. Methods: This isi quantitative research with the observasional method using cross-sectional study, sample were taken as many as 36 people as respondents conducted by using proportionate random sampling. Data collected through observation, interview and documentation by using questionnaire SPAF questionnaire (The short Premenstrual Assessment Form) and menstrual diary Result: Female result in the intensive care unit who premenstrual syndrome have less performance the correlation value of 0,522, significant with p-value 0,001 Conclusion: This study showed that there is relationship between premenstrual syndrome to the performance ICU (intensive care unit) nurses in makassar city hospital
\end{abstract}




\begin{tabular}{lr}
\hline Keyword: & $\begin{array}{r}\text { Coresponden author: } \\
\text { SPM; }\end{array}$ \\
ICU; & Email: $\begin{array}{c}\text { ekayanti.h.a@gmail.com } \\
\text { SPAF; }\end{array}$ \\
& artikel dengan akses terbuka dibawah lisensi CC BY -4.0 \\
\hline
\end{tabular}

\section{Pendahuluan}

Perawat memiliki kedudukan penting dalam menghasilkan kualitas pelayanan kesehatan di rumah sakit, karena pelayanan yang tentunya dilaksanakan secara berkesinambungan merupakan kelebihan tersendiri dibanding pelayanan lainnya. Perawat merupakan tenaga kesehatan yang jumlah dan kebutuhannya paling banyak diantara tenaga kesehatan yang lain. Maka dari itu rumah sakit semestinya memiliki perawat yang berkinerja baik yang akan menunjang kinerja rumah sakit sehingga dapat tercapai kepuasan pelanggan atau pasien. Peningkatan kinerja sangat diperlukan tenaga kerja yang sehat dan produktif. Adapun beberapa keadaaan yang dapat menurunkan kinerja disebabkan permasalahan kondisi fisik wanita lebih kompleks. Salah satu proses fisiologis yang terjadi pada perawat wanita sehingga mempengaruhi kinerja perawat disebabkan oleh adanya masa menstruasi

Sindrom Premenstruasi mempengaruhi kehidupan sehari-hari wanita dan dapat menurunkan kualitas hidup dan keterampilan sosial mereka (Chayachinda, et all, 2008). Tingkat keparahan gejala sindrom premenstruasi dikaitkan dengan durasinya dalam bagaimana itu merusak kehidupan sehari-hari wanita(Chayachinda et al., 2008) (Chayachinda et al., 2008; Choi et al., 2010). Gejala fisik sindrom premenstruasi, seperti iritabilitas dan otot, persendian, punggung, dan sakit perut, lebih umum daripada gejala mental(Chayachinda et al., 2008). Gejala-gejala ini bersifat siklik; Namun, tingkat keparahan dan luasnya dapat bervariasi(Chayachinda et al., 2008).

Tanggung jawab perawat dalam praktik klinis penting. Kondisi kerja yang penuh tekanan dan berat, risiko pekerjaan, dan kepuasan kerja yang rendah menurunkan kinerja pekerjaan perawat(Demir, etal 2006). Dewan Perawat Internasional(DirekvandMoghadam, etal, 2014) melaporkan bahwa lingkungan kerja yang tidak sehat mengurangi kinerja perawat, Frekuensi sindrom premenstruasi pada perawat, yang dapat secara negatif mempengaruhi kualitas kehidupan kerja, dilaporkan sebesar 25,1\%(Opollo, etall, 2014).

Dalam sebuah penelitian yang dilakukan pada perawat Thailand, prevalensi sindrom premenstruasi dilaporkan sebagai 25,1\%(Opollo et al., 2014). Kejadian PMS pada wanita yang bekerja di perawatan kesehatan telah dilaporkan 20,1\%(Ozisik Karaman, etall, 2012). Penelitian yang dilakukan pada perawat turki menunjukkan prevalensi sebesar $38,1 \%$ Perawat dengan sindrom premenstruasi mengalami penurunan tingkat kualitas hidup terkait pekerjaan dalam kehidupan profesional mereka(Kahyaoglu Sut, etal, 2016).

Penelitian nona mu'minun yang telah membuktikan hubungan Sindrom Premenstruasi terhadap produktivitas tenaga kerja di Kawasan Industri Kima Makassar, dimana ada pengaruh variabel kejadian sindrom premenstruasi $(p=0,013)$, keluhan sindrom premenstruasi $(\mathrm{p}=0,001)$, keparahan sindrom premenstruasi $(\mathrm{p}=0,001)$ terhadap produktivitas ( $p>0,05)(M u$ 'minun, 2012). Sindrom Premenstruasi merupakan hal yang pernah dialami oleh lebih dari 90\% wanita(Balaha, etal, 2010). Delapan sampai dua puluh persen diantaraya bahkan mengalami gejala yang berat sehingga memerlukan pengobatan(Delara et al., 2012).

Berdasarkan beberapa literatur yang telah dipaparkan, peneliti tertarik untuk mengetahui hubungan sindrom premenstruasi terhadap kinerja perawat di ruang icu (intensive care unit) Rumah Sakit Kota Makassar. 


\section{Metode}

Jenis penelitian yang digunakan adalah penelitian kuantitatif dengan metode observasional menggunakan rancangan crossectional study. Desain ini dimaksudkan untuk mempelajari korelasi antara premenstruasi terhadap kinerja perawat Intensive Care Unit dirumah sakit makassar. Penelitian ini dilakukan di beberapa rumah sakit diantaranya rumah sakit DR. Wahidin Sudirohusodo, Rumah Sakit Unhas, Rumah sakit Hikmah dan Rumah Sakit Sayang Rakyat dengan populasi sebanyak 36 sampel. Waktu pelaksanaan penelitian ini dilakukan pada tahun 2017. Metode Sampel yang digunakan yakni secara proportionate random sampling. Dan telah memenuhi syarat kriteria inklusi dan ekslusi sebagai berikut:

Inklusi:

1. Perawat tetap yang berada di Ruang Intensive Care Unit

2. Perawat yang masih mengalami haid

Ekslusi:

1. Perawat dalam proses cuti

2. Perawat dalam keadaan hamil

\section{Hasil Dan Pembahasan}

Tabel 1. Distribusi Karakteristik Perawat icu (intensive care unit) di Beberapa Rumah Sakit Kota Makassar

\begin{tabular}{lcc}
\hline \multicolumn{1}{c}{ Karakteristik Responden } & (n) & (\%) \\
\hline Umur & 8 & \\
$\quad 20-27$ thn & 20 & 22 \\
$28-35$ thn & 8 & 56 \\
$\quad 36-43$ thn & 12 & 22 \\
Pendidikan & 24 & 33 \\
$\quad$ Diploma & & 67 \\
$\quad$ S1 & 24 & 67 \\
Status Pernikahan & 12 & 33 \\
$\quad$ Menikah & & \\
$\quad$ Belum Menikah & 20 & 57 \\
Masa Kerja & 16 & 43 \\
$\quad<7$ thn & & \\
$\quad \geq 7$ thn & 14 & 40 \\
Lama Haid & 22 & 60 \\
$\quad \leq 6$ hr & & \\
$\quad>6$ hr & 19 & 53 \\
Siklus Haid & 17 & 47 \\
$\quad$ Teratur & & \\
$\quad$ Tidak Teratur
\end{tabular}

Sumber: Data Primer

Berdasarkan tabel diatas diketahui bahwa responden terbanyak adalah usianya 28-35 tahun dan selebihnya berusia (20-27 tahun) dan (36-43) tahun. Hal ini menunjukkan bahwa usia perawat icu (intensive care unit) dianggap masih mampu bekerja secara produktif. Kategori pendidikan perawat terbanyak adalah berlatar pendidikan S1. Hal ini menunjukkan bahwa pendidikan perawat icu (intensive care unit) merupakan hal yang dianggap cukup berpengaruh terhadap tindakan yang dilakukan kepada pasien di ruang 
intensive care unit sesuai dengan kompetensi perawat dan perawat terbanyak berkategori telah menikah.

Berdasarkan tabel diatas juga bahwa sebagian besar perawat memiliki masa kerja $\geq 7$ tahun dan selebihnya $<7$ tahun. Hal ini menunjukkan bahwa masa kerja perawat yang lama diruang icu (intensive care unit) dianggap cukup berpengalaman dalam melakukan asuhan keperawatan kepada pasien. Sebagian besar perawat mengalami lama haid (hari) $>6$ hari. Hal ini menunjukkan bahwa lama haid (hari) perawat icu (intensive care unit) masih dianggap normal/wajar dan perawat terbanyak mengalami siklus haid teratur. Hal ini menunjukkan bahwa status haid pada perawat dianggap normal.

Tabel 2. Distribusi Sindrom Premenstruasi berdasarkan Kinerja Perawat icu (intensive care unit) di Beberapa Rumah Sakit Kota Makassar

\begin{tabular}{|c|c|c|c|c|c|c|c|c|}
\hline \multirow{3}{*}{$\begin{array}{c}\text { Sindrom } \\
\text { Premenstruasi }\end{array}$} & \multicolumn{6}{|c|}{ Kinerja } & \multirow{2}{*}{\multicolumn{2}{|c|}{ Total }} \\
\hline & \multicolumn{2}{|c|}{ Baik } & \multicolumn{2}{|c|}{ Cukup } & \multicolumn{2}{|c|}{ Kurang } & & \\
\hline & $\mathrm{n}$ & $\%$ & $\mathrm{n}$ & $\%$ & $\mathrm{n}$ & $\%$ & $\mathrm{n}$ & $\%$ \\
\hline Ringan & 9 & 82 & 1 & 9 & 1 & 9 & 10 & 100 \\
\hline Sedang & 7 & 70 & 2 & 20 & 1 & 10 & 11 & 100 \\
\hline Berat & 1 & 7 & 1 & 7 & 13 & 86 & 15 & 100 \\
\hline Total & $\begin{array}{l}1 \\
6\end{array}$ & 44 & 4 & 11 & 16 & 44 & 16 & 100 \\
\hline
\end{tabular}

Sumber: Data Primer

Tabel 3. Analisis Uji Korelasi berdasarkan Variabel Penelitian di Beberapa Rumah Sakit Kota Makassar

\begin{tabular}{|c|c|c|c|c|c|c|}
\hline \multicolumn{7}{|c|}{ Directional Measures } \\
\hline & & & Value & Asy & Appr & Appr \\
\hline & & & & $\mathrm{mp}$. & ox. & ox. \\
\hline & & & & Std. & & \\
\hline & & & & Erro & & \\
\hline & & & & & & \\
\hline \multirow{7}{*}{$\begin{array}{l}\text { Ordinal } \\
\text { by } \\
\text { Ordinal }\end{array}$} & \multirow{7}{*}{$\begin{array}{l}\text { Somer } \\
s^{\prime} d\end{array}$} & Symmetric & 0,663 & 0,10 & 6,77 & 0,00 \\
\hline & & & & 2 & 8 & 1 \\
\hline & & Kelompok sindrom pre & 0,700 & 0,11 & 6,77 & 0,00 \\
\hline & & menstruasi Dependent & & 0 & 8 & 1 \\
\hline & & kelompok kinerja & 0,631 & 0,10 & 6,77 & 0,00 \\
\hline & & respondenn & & 0 & 8 & 1 \\
\hline & & Dependent & & & & \\
\hline \multicolumn{7}{|c|}{ a. Not assuming the null hypothesis. } \\
\hline \multicolumn{7}{|c|}{ b. Using the asymptotic standard error assuming the null hypothesis. } \\
\hline \multirow{4}{*}{\multicolumn{3}{|c|}{ Variabel Penelitian }} & \multicolumn{4}{|c|}{ UJI STATISTIK } \\
\hline & & & Gamma & & p-value & \\
\hline & & & $\&$ & & & \\
\hline & & & $\begin{array}{c}\text { Somer's } \\
\text { d }\end{array}$ & & & \\
\hline \multicolumn{3}{|c|}{ Sindrom Premenstruasi $\rightarrow$ Kinerja } & 0,631 & & 0,001 & \\
\hline
\end{tabular}

\section{Sumber: Data Primer}

Hasil analisis uji korelasi antara variabel sindrom premenstruasi terhadap kinerja menunjukkan terdapat hubungan yang signifikan $(p=0,001)$ dengan besar koefisien korelasi sebesar $\mathrm{r}=0,631$ 
Sindrom premenstruasi terjadi hampir pada semua wanita. setiap wanita mengalami keluhan-keluhan sindrom premenstrusi yang berbeda. Hasil penelitian menunjukkan bahwa perawat wanita di ruang icu (intensive care unit) yang tidak mengalami keluhan sindrom premenstruasi yang berat menunjukkan kinerja yang kurang sebesar $86 \%$.

Hasil uji statistik menunjukkan terdapat hubungan antara variabel sindrom premenstruasi terhadap kinerja pada perawat dengan nilai $p=0,001$, dengan nilai koefisien korelasi sebesar 0,631 yang berarti variabel sindrom premenstruasi dengan variabel kinerja memiliki korelasi.

Beberapa perawat mengalami keluhan yang sangat berat ketika menjelang menstruasi. beberapa yang dikeluhkan oleh perawat merasakan nyeri pada perut bagian bawah, nyeri pada punggung, sendi otot, dan disaat yang sama perawat merasa kewalahan dalam menghadapi tuntutan sehingga proses asuhan keperawatan yang dilakukan terhadap pasien kurang maksimal. Keadaaan tersebut diperkuat oleh pengakuan beberapa perawat yang bekerja di icu (intensive care unit) dimana menjelang menstruasi atau sindrom premenstruasi terkadang melibatkan petugas lain dalam memvalidasi respon pasien, mengevaluasi perkembangan pada pasien tertentu, merencanakan tindakan berdasar pada kemampuan pasien tertentu, hingga jarang melibatkan keluarga pasien dalam melakukan asuhan keperawatan. Keadaan-keadaan ini cukup mempengaruhi kinerja seseorang khususnya pada perawat intensive care unit.

Sejalan dengan penelitian yang dilakukan oleh nona mu'minun yang telah membuktikan hubungan Sindrom Premenstruasi terhadap produktivitas tenaga kerja di Kawasan Industri Kima Makassar, dimana ada pengaruh variabel kejadian sindrom premenstruasi $(p=0,013)$, keluhan sindrom premenstruasi $(p=0,001)$, keparahan sindrom premenstruasi $(p=0,001)$ terhadap produktivitas $(p>0,05)(M u ' m i n u n, 2012)$. Hasil penelitian diatas juga ditemukan sangat signifikan antara sindrom sindrom premenstruasi dan sindrom non premenstruasi yang mana mempelajari kelompok perempuan mengenai efek dari gejala sindrom premenstruasi pada kinerja pada kapasitas kerja mereka. Secara khusus, psikologis dan gejala fisik membuat kinerja mereka lebih buruk(Kahyaoglu Sut \& Mestogullari, 2016). Sejalan dengan Hasil penelitian Schmelzer dkk., (2015) menunjukkan bahwa wanita yang mengalami sindrom premenstruasi cenderung memiliki produktivitas yang menurun(Schmelzer et al., 2015).

\section{Kesimpulan Dan Saran}

Sindrom Premenstruasi memiliki hubungan yang erat terhadap kinerja perawat icu (intensive care unit) di rumah sakit kota makassar. Pihak rumah sakit khususnya kepala icu (intensive care unit) agar melakukan pengaturan kerja pada perawat yang mengalami sindrom premenstruasi. Untuk itu hendaknya perawat yang mengalami sindrom premenstruasi agar dapat berpindah waktu shift ke pagi hari, sehingga tidak mempengaruhi kinerja.

\section{Ucapan Terima Kasih}

Ucapan terima kasih kepada Direktur DR. Wahidin Sudirohusodo, Rumah Sakit Hasanuddin, Rumah Sakit hikmah, Rumah Sakit Sayang Rakyat dan kepala ruangan ICU (intensive care unit) yang mana telah mengizinkan penulis untuk melakukan penelitian. 


\section{Daftar Rujukan}

Balaha, M. H., Amr, M. A. E. M., Al Moghannum, M. S., \& Al Muhaidab, N. S. (2010). The phenomenology of premenstrual syndrome in female medical students: A cross sectional study. Pan African Medical Journal, 5. https://doi.org/10.1002/da

Chayachinda, C., Rattanachaiyanont, M., Phattharayuttawat, S., \& Kooptiwoot, S. (2008). Premenstrual syndrome in Thai nurses. Journal of Psychosomatic Obstetrics and Gynecology. https://doi.org/10.1080/01674820801970306

Choi, D., Lee, D. Y., Lehert, P., Lee, I. S., Kim, S. H., \& Dennerstein, L. (2010). The impact of premenstrual symptoms on activities of daily life in Korean women. Journal of Psychosomatic Obstetrics and Gynecology. https://doi.org/10.3109/01674820903573920

Delara, M., Ghofranipour, F., Azadfallah, P., Tavafian, S. S., Kazemnejad, A., \& Montazeri, A. (2012). Health related quality of life among adolescents with premenstrual disorders: A cross sectional study. Health and Quality of Life Outcomes. https://doi.org/10.1186/1477-7525-10-1

Demir, B., Yıldız Algül, L., \& Güvendağ Güven, E. S. (2006). The incidence and the contributing factors of premenstrual syndrome in health working women. Turk Soc Obstet Gynecol., 4(3), 262-270.

Direkvand-Moghadam, A., Sayehmiri, K., Delpisheh, A., \& Satar, K. (2014). Epidemiology of premenstrual syndrome, a systematic review and meta-analysis study. Journal of Clinical and Diagnostic Research. https://doi.org/10.7860/JCDR/2014/8024.4021

Kahyaoglu Sut, H., \& Mestogullari, E. (2016). Effect of Premenstrual Syndrome on WorkRelated Quality of Life in Turkish Nurses. Safety and Health at Work, 7(1), 78-82. https://doi.org/10.1016/j.shaw.2015.09.001

Mu'minun, N. (2012). Pengaruh Sindroma Premenstruasi Terhadap Produktivitas Tenaga Kerja Wanita pada PT Ekasari Lestari dan PT Kelola Mina Laut Kota Makassar. Retrieved from http://sinta.ristekbrin.go.id/authors/detail?id=6717803\&view=overview

Opollo, J. G., Gray, J., \& Spies, L. A. (2014). Work-related quality of life of Ugandan healthcare workers. International Nursing Review. https://doi.org/10.1111/inr.12077

Ozisik Karaman, H. I., Tanriverdi, G., \& Degirmenci, Y. (2012). Subjective sleep quality in premenstrual syndrome. Gynecological Endocrinology. https://doi.org/10.3109/09513590.2011.650769

Schmelzer, K., Ditzen, B., Weise, C., Andersson, G., Hiller, W., \& Kleinstäuber, M. (2015). Clinical Profiles of Premenstrual Experiences Among Women Having Premenstrual Syndrome (PMS): Affective Changes Predominate and Relate to Social and Occupational Functioning. Health Care for Women International. https://doi.org/10.1080/07399332.2014.954701 